\title{
Analysis of trends in the variability of daily and monthly historical temperature measurements
}

\author{
Patrick J . Michaels ${ }^{1, *}$, Robert C. Balling J r ${ }^{2}$, Russell S. Vose ${ }^{2}$, Paul C. Knappenberger ${ }^{1}$ \\ ${ }^{1}$ Department of Environmental Sciences, University of Virginia, Charlottesville, Virginia 22903, USA \\ ${ }^{2}$ Office of Climatology and Department of G eography, A rizona State University, Tempe, A rizona 85287, USA
}

\begin{abstract}
This investigation analyzes trends in the variability of daily and monthly near-surface air temperatures. We examined the $5^{\circ}$ latitude by $5^{\circ}$ longitude monthly temperature anomalies available for many grids around the world. Overall, the trend in intra-annual temperature variance is towards reduced variability and is highly significant over the past 50 and $100 \mathrm{yr}$. We then examined daily maximum and minimum temperatures from the United States, China, and the former Soviet Union for intra-monthly variability in J anuary and J uly. M ost of the trends also indicated declining variability. A final approach examined the occurrence of record-setting daily maximum and minimum temperatures from the same countries. We found no evidence for an increase in record temperatures. The fact that intra-annual and intra-monthly variance is declining suggests that we should see fewer record temperatures in recent years. There is some evidence for this in the daily data. In general, our results argue against the proposition that temperatures have become more variable as global temperatures have changed in this century.
\end{abstract}

KEY WORDS: Climate change $\cdot$ M onthly temperature variability · Daily temperature variability

\section{INTRODUCTION}

The continued buildup of greenhouse gases may force any number of changes to the climate system including the highly-popularized prediction for an increase in mean global temperatures. However, as noted by many investigators (Hansen et al. 1988, M earns et al. 1990, Barrow \& Hulme 1996, J oubert \& Hewitson 1997), changes in temperature variability are also important in determining the future temperature distributions. While the newer numerical models of climate predict less warming with realistic greenhouse changes than do earlier versions (Kerr 1997, Mitchell \& J ohns 1997), predictions of temperature variability remain inconsistent.

For example, Gregory \& Mitchell (1995) concluded that changes in variability could greatly differ from season to season, and were highly dependent upon local physical processes. Under doubled carbon dioxide conditions, their experiment revealed decreases in temperature variability during European winter be-

*E-mail: pjm8x@virginia.edu cause of reduced land/sea temperature differences, but increased summer variability because of changes in the surface radiation budget.

Empirical studies of observed temperature variability are no more conclusive. Parker et al. (1992) examined the long temperature record from central England (Manley 1974) and found no evidence of increased variance in recent decades. Parker et al. (1994) compared interannual seasonal temperature anomalies from the 1954-1973 period to the 1974-1993 period for most of the globe. They found a small increase in variability overall with an especially large increase in central North America. However, Karl et al. (1995) concluded that an increase in $\mathrm{CO}_{2}$ should decrease high frequency temperature variance, and they found that day-to-day variability during the twentieth century is down in the Northern Hemisphere, particularly in the United States and China. Karl et al. (1997, p. 81) later stated, 'Projections of the day-to-day changes in temperature are less certain than those of the mean, but observations have suggested that this variability in much of the Northern Hemisphere's mid-latitudes has decreased as the climate has become 
warmer. Some computer models also project decreases in variability.'

The entire issue is further confused by the many operational definitions and statistical approaches that have been used to quantify temperature variability. In addition, the literature contains many articles on trends in extreme temperatures which may be related to changes in the mean and/or changes in the variance (M earns et al. 1984, Hansen et al. 1988, Balling et al. 1990, Tarleton \& Katz 1995, Barrow \& Hulme 1996). But while the scientific debate on this dimension of global change continues, the public seems convinced that the world's weather has become more variable in the recent decades.

The purpose of this paper is to present the results from 3 different empirical analyses used to address interrelated issues involving changes in temperature variability and trends in record-breaking extreme temperatures. The calculations applied are relatively simple and the datasets are widely available and from large areas of the earth's surface. The techniques are applied consistently from place to place, and several of the procedures allow areal averaging which provides an indication of temporal trends in variability over large areas, including the entire earth. All of these analyses and results should be useful in resolving some of the fundamental questions regarding trends in temperature variability during the period of historical records. An understanding of the historical record will provide us with a better insight into future trends under a changing climate.

\section{TEM PERATURE DATA SETS}

The 1995 report of the United Nations Intergovernmental Panel on Climate Change (IPCC) describes a monthly near-surface air temperature dataset that is available on the internet and is widely used in climate research (Houghton et al. 1996). The land surface air temperatures are taken from the $5^{\circ}$ latitude by $5^{\circ}$ longitude grid cell temperature data developed and described by J ones (1994). J ones carefully assessed the homogeneity and representativeness of each time series from 2961 stations. He converted the monthly station observations into the $5^{\circ}$ latitude by $5^{\circ}$ Iongitude grid-box data, and all values are expressed as deviations (anomalies) from a reference period defined as 1961 to 1990. The IPCC monthly temperature data for the oceanic areas were extracted from the data generated and described by Folland \& Parker (1995). The original data come from millions of observations from ships, and a physical-empirical method is applied to the raw data to eliminate inhomogeneities that impact the oceanic temperatures.
Daily maximum and minimum temperature time series for the United States, China, and the former Soviet Union were acquired from the Carbon Dioxide Information Analysis Center (CDIAC) at Oak Ridge National Laboratory (Oak Ridge, TN, USA). The record from the former Soviet Union consists of 223 stations compiled initially by the Research Institute of Hydrometeorological Information in Obninsk, Russia (Razuvaev et al. 1993). This network varies considerably through time with some stations opening in the late 19th century, most opening in the mid-1930s, and all ending by 1989. Daily temperature data for the People's Republic of China were assembled initially by the Chinese Academy of Sciences in Beijing, China. The network consists of 191 stations with nearly continuous records extending from 1951 to 1990. Finally, the 1062-station subset of the United States Historical Climatology Network prepared by the National Climatic Data Center was added to the analyses (Hughes et al. 1992). Many of these stations opened in the late 19th century and most continue through 1995.

Each of these 3 daily maximum and minimum temperature datasets is considered to be of high quality and potentially useful in the analyses of changes in variability over the period of record. The source organizations and CDIAC subjected these data to rigorous quality assurance checks that eliminated outliers, major discontinuities, and other relatively standard data problems. However, in each network the time of observation does vary from station to station and year to year, and urban influences have not been explicitly addressed, although most stations in the former Soviet Union and the United States are predominantly rural.

\section{AN ALYSES AND RESULTS}

\subsection{M onthly temperature variation}

We first looked at the variability of the monthly temperature anomalies within each year using the IPCC monthly gridcell temperature anomaly dataset. For each gridcell in this dataset which contained a complete set of 12 monthly anomalies in any year, we simply calculated the intra-annual variance in the temperature anomalies for that year as:

$$
\text { Variance }=\frac{\left(\sum_{i=1}^{N} X_{i}^{2}\right)-N \bar{X}^{2}}{N-1}
$$

where $\mathrm{X}$ represents the monthly temperature anomalies and $\mathrm{N}$ is the number of months (equal to 12 ). We then calculated the best fit least-squares linear trend in the variance time-series for each gridcell for the most recent 50 and $100 \mathrm{yr}$ periods, and only calculated the 
trend for cells with no more than $10 \%$ of the years missing over the selected time period.

For the most recent $50 \mathrm{yr}$ (1947 to 1996), 1041 (out of a possible 2592) gridcells have valid data, covering $50.5 \%$ of the earth. The regional pattern shows a gen- eral decline of the within-year variance of the monthly temperature anomalies in most locations, although the mid-to-upper latitude land areas of the Northern Hemisphere show increases in the intra-annual variance levels (Fig. 1). Fig. 2 shows the spatial pattern of

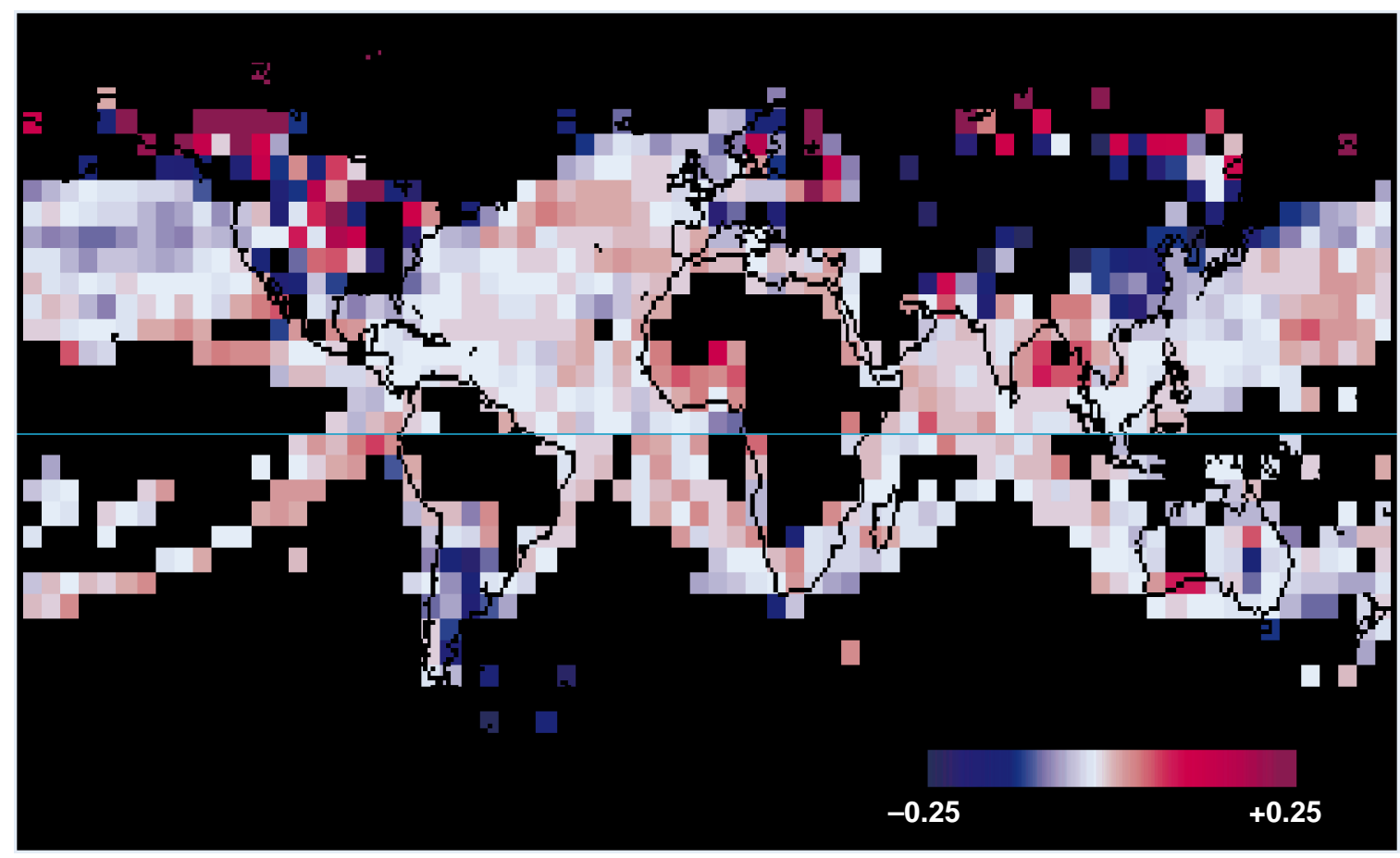

Fig. 1. Trends in intra-annual variance $\left({ }^{\circ} \mathrm{C}^{2} \mathrm{decade}^{-1}\right)$ for the period 1947 to 1996

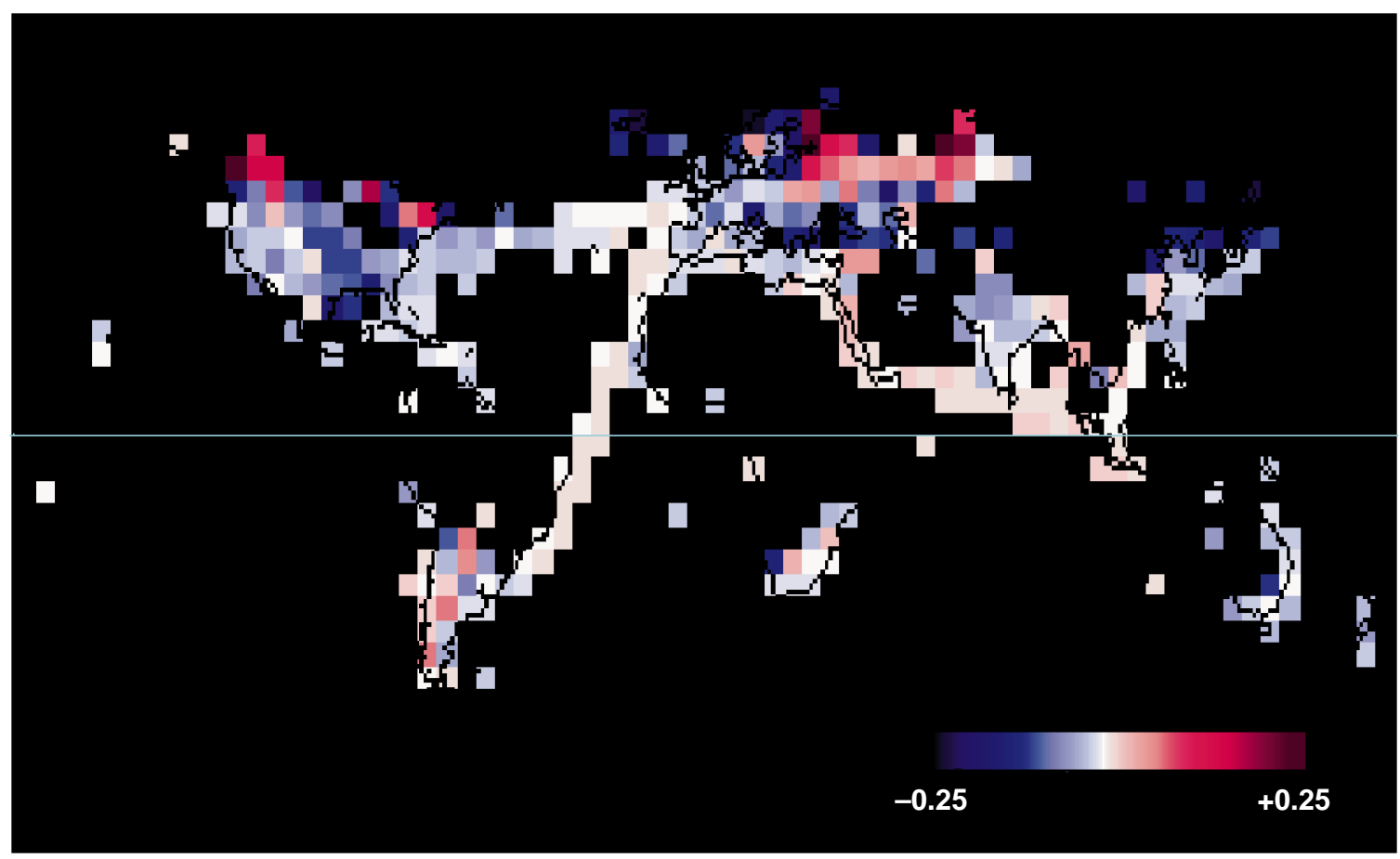

Fig. 2. Trends in intra-annual variance $\left({ }^{\circ} \mathrm{C}^{2} \mathrm{decade}^{-1}\right)$ for the period 1897 to 1996 
the trends in the variance time-series using the $100 \mathrm{yr}$ period (1897 to 1996). While this analysis only included 393 cells covering $18.4 \%$ of the earth, the spatial pattern continues to show an overall decline in most areas, but an increase in variance in northern North America and northern Eurasia.

For the period 1947 to 1996, we produced a single areally-weighted average variance term for each year using the 1041 cells with nearly continuous data. This produced a time-series of intra-annual variance levels from 1947 to 1996 over a large spatial scale (Fig. 3). The trend in this time-series is towards decreasing intra-annual variance of monthly temperature anomalies and is highly significant $(\Delta$ Variance/ $\Delta$ Decade $=$ $-0.11^{\circ} \mathrm{C}^{2}$ decade $\left.^{-1}, r=-0.58\right)$. We repeated the analyses for the 313 cells with continuous data from 1897 to 1996, and found a similar result $\left(\Delta\right.$ Variance $/ \Delta$ Decade $=-0.06^{\circ} \mathrm{C}^{2} \mathrm{decade}^{-1}$, $r=-0.44)$. The Pearson product-moment correlation coefficient between the long and short time series is +0.90 , indicating that using the $100 \mathrm{yr}$ dataset, even though it is much reduced in spatial extent, provides a fair representation of large-scale historical trends.

Finally, we compared the IPCC mean annual global temperature anomalies to the variance time-series for the 1897-1996 period (Fig. 4); the statistically significant correlation coefficient is -0.33 . The result indicates that as the world warms, the intra-annual variance decreases at a statistically significant rate. Looking at only the 1947-1996 period, the correlation coefficient between global temperature variance and global temperature is -0.34 .

\subsection{Daily temperature variance}

We then performed an analysis to investigate the trends in the variation of the daily minimum and maximum temperatures within a winter and summer month. To do this, we calculated the intra-monthly variance in daily maximum and minimum temperatures for each J anuary and each J uly for each of the 223 stations in the former Soviet Union, the 1062 stations in the United States, and the 198 stations in China. A minimum of 29 J anuary or J uly days with actual data was required for any one month, or the monthly variance value for that month was considered missing. We then separately determined the trend in the daily maximum and minimum temperature variance values for each station for J anuary and J uly. We eliminated any station with less than $50 \mathrm{yr}$ of monthly variance values in the United States and the former
Soviet Union, and, since the Chinese stations had a shorter period of record, we required only $30 \mathrm{yr}$ of data for stations there to be included in the analysis. Finally, we calculated the mean and standard deviation of the variance trend values for each of the 3 regional databases.

Several key patterns stand out in the mean trends in daily temperature variance values from the 3 regions (Table 1). Overall, variance in daily maximum and minimum temperatures is generally trending downwards (i.e. temperatures are becoming less variable) through the period of historical records. J anuary declines are on average nearly 10 times greater than declines in J uly. Variance in minimum temperatures is declining more than variance in maximum tempera-

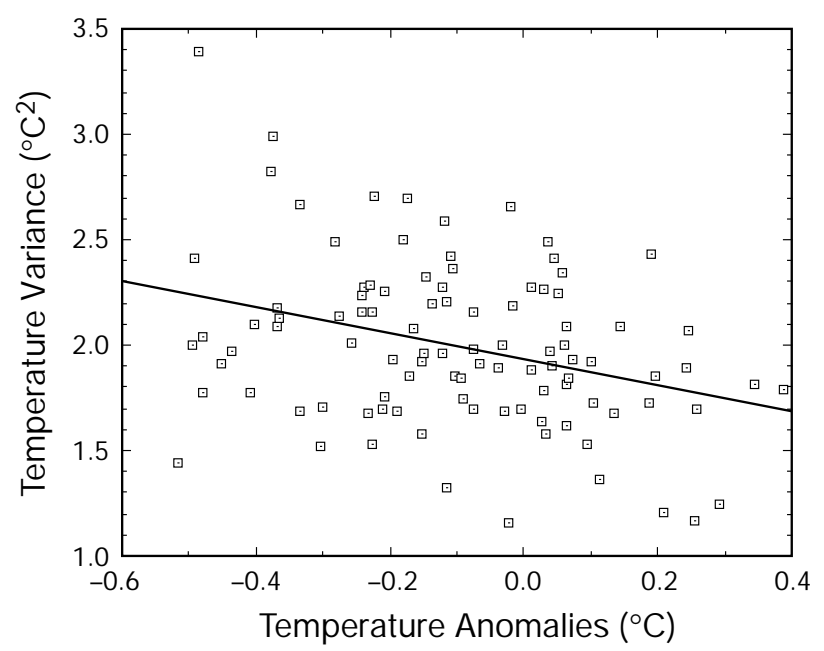

Fig. 4. Aggregate intra-annual temperature variance versus annual global temperature anomalies for the 1897-1996 timeseries 
Table 1 . Mean linear trend $\left({ }^{\circ} \mathrm{C}^{2}\right.$ decade $\left.^{-1}\right)$ in daily temperature variance values

\begin{tabular}{|lrrr|}
\hline & USA & China & Former Soviet Union \\
\hline M aximum temp. & & & \\
J anuary & -0.19 & -1.13 & 0.07 \\
July & -0.13 & 0.06 & -0.02 \\
Minimum temp. & & & \\
J anuary & -0.26 & -1.32 & -0.37 \\
July & -0.19 & 0.06 & -0.08 \\
\hline
\end{tabular}

tures. However, the spatial standard deviations associated with these regional mean variance trend values are in every case as large, or larger than the mean shown in Table 1. This suggests that the mean trend values are not statistically significantly different from zero. However, $12 \%$ of the stations show statistically significant negative trends ( $\alpha=0.05$ ) while $6 \%$ show a significant increase. This latter value is obviously not different from the $5 \%$ expected at this significance level.

\subsection{Record-breaking daily temperatures}

The final set of analyses we performed was aimed at exploring the temporal trends in the occurrence of record-breaking extreme temperatures. For each station, and for each of the 4 temperature records (high maximum, low maximum, high minimum, low minimum), we developed a string of 365 values, one for each day of the year. For each day, we determined the year in which the most extreme (record-breaking) temperature occurred; we also determined the time when the daily temperature series began and ended for each station. If there is a trend toward an increasing frequency of record temperatures in the more recent years, the mean of the 365 values representing the years in which daily temperature records were set, $Y_{\text {mean }}$, would be greater than the mid-point of the time series, $Y_{\text {mid. }}$. We calculated the standard deviation, $\mathrm{s}$, in the time series of 365 year values, and finally, we produced standardized z-scores of the difference between the time-series mid-point and the mean of the 365 year values by dividing the difference by the standard deviation, $Z_{\Delta Y}=\left(Y_{\text {mean }}-Y_{\text {mid }}\right) / s$. In this way, we were able to combine the data from individual stations into regional aggregates. We can assess the statistical significance of the $z_{\Delta Y}$ values by using a table of standard normal probabilities. We performed these calculations separately for record-breaking high maximum temperature, low maximum temperature, high minimum temperature, and low minimum temperature. We eliminated stations with less than $50 \mathrm{yr}$ of record or more than $5 \%$ missing data in the United States and the former Soviet Union and stations with less than $30 \mathrm{yr}$ of record or more than $5 \%$ missing data in China. We produced a regional aggregate mean value through simple averaging of the $z_{\Delta Y}$ values for every station in each region.

The resulting regional aggregated $z_{\Delta Y}$ values are presented in Table 2 , and although the $z_{\Delta Y}$ values are not high enough to be judged statistically significant, several key results emerge. The average year in which daytime record high temperatures were set is prior to the midpoint of the time-series for both the United States and China station aggregates, and very near to it for the Russian aggregate. This indicates an overall tendency for record-breaking maximum temperatures to have occurred earlier in the temporal record, although the lack of statistical significance means that these results could have occurred by chance alone. The same holds true for record low minimum temperatures where, although all 3 regions showed the tendency for record-setting extremely low temperature to have occurred in the early part of the record, the results were not statistically significant. Therefore, at our level of aggregation, we cannot support the statement in the recent IPCC report (Houghton et al. 1996, p. 138) which says, 'There has been a clear trend to fewer extremely low minimum temperatures in several widely separated areas in recent decades.' However, our results do support the IPCC assertion that '[w]idespread significant changes in extreme high temperature events have not been observed.'

Although we eliminated stations with more than $5 \%$ missing data, there remained a significant and positive relationship between some of the $z_{\Delta Y}$ values and the percent missing data. Because missing data tend to occur early in the observations, thereby reducing the opportunity for record-breaking values during the periods with missing data problems, a positive relationship exists between percent missing data and the $z_{\Delta Y}$ values. For example, the $+0.03 z_{\Delta Y}$ value for the high maximum temperatures in the former Soviet Union actually reduces to -0.01 when this effect is controlled for using a simple regression analysis. The other $z_{\Delta Y}$ values would be similarly corrected downward for the former

Table 2. $z_{\Delta Y}$ values indicating temporal tendency for recordbreaking temperatures

\begin{tabular}{|lrrr|}
\hline & USA & China & Former Soviet Union \\
\hline M aximum temp. & & & \\
High & -0.24 & -0.16 & 0.03 \\
Low & -0.07 & -0.11 & -0.01 \\
Minimum temp. & & & \\
$\quad$ High & -0.14 & 0.02 & 0.14 \\
Low & -0.16 & -0.31 & -0.15 \\
\hline
\end{tabular}


Soviet Union, but in China and the United States, no statistically significant relationship exists between the $z_{\Delta Y}$ values and the percent missing data.

\section{DISCUSSION AND CONCLUSIONS}

Our results vary considerably with the popular perceptions about a warming world. We find decreasing variability within years and within months. In addition, we find a negative correlation between global average temperature departures and global-scale monthly temperature variance, which means that warmer global temperatures are associated with lower intra-annual temperature variability (i.e. more stable temperatures). We also find no evidence for an increasing frequency in the number of days in which record high temperatures occur, and a statistically insignificant downward trend in the frequency of days in which record low temperatures are set.

Our results are consistent with a number of recent studies (e.g. Karl et al. 1995, Thompson 1995, Knappenberger et al. 1996) that show very subtle (and nonobvious) climate responses that are highly consistent with greenhouse physics. The enhancement of the levels of atmospheric carbon dioxide is forecast by most global climate models to raise the temperatures the most during the wintertime in the high latitudes (Houghton et al. 1996). Recent results by Balling et al. (1998) show that this seems to be occurring in the coldest and driest airmasses in the Northern Hemisphere-those found during the winter over Siberia and northwestern N orth America. This reduction of the equator-to-pole temperature gradient results in a climate that is more 'summerlike' (or less 'winterlike'). Globally, warm seasons are characterized by lower month-to-month and day-to-day variability. This is consistent with our results which show that the variance in daily temperatures has been declining much more during J anuary than J uly in our 3 regions in the Northern Hemisphere.

These results underscore an evolving concept of 'moderate' climate change (as opposed to rapid, Iarge and dangerous change) that is also supported by recent modelling studies such as those described by Kerr (1997) and M itchell \& J ohns (1997). These models produce only about a degree and a half (C) of warming over the next century when their results are adjusted to reflect a more realistic value $\left(0.7 \% \mathrm{yr}^{-1}\right)$ for the increase of effective carbon dioxide than was actually used in the models. A future temperature change of $1.5^{\circ} \mathrm{C}$ is near the low end of the IPCC (1995) range of 1 to $3.5^{\circ} \mathrm{C}$ for the forecast of global average temperature increase by the year 2100 . The results of these new models, along with our results and other recent findings (e.g. Balling et al. 1998), suggest that the climate of the next century will be characterized by a modest warming, primarily in the high latitudes in winter, with decreased season-to-season and day-today temperature fluctuations.

\section{LITERATURE CITED}

Balling RC, Michaels PJ , Knappenberger PC (1998) Analysis of winter and summer warming rates in gridded temperature time series. Clim Res 9:175-181

Balling RC J r, Skindlov J A, Phillips DH (1990) The impact of increasing summer mean temperatures on extreme maximum and minimum temperatures in Phoenix, Arizona. J Clim 3:1491-1494

Barrow EM, Hulme M (1996) Changing probabilities of daily temperature extremes in the UK related to future global warming and changes in climate variability. Clim Res 6: 21-31

Folland CK, Parker DE (1995) Correction of instrumental biases in historical sea surface temperature data. Q J R Meteorol Soc 121:319-367

Gregory J M, M itchell J FB (1995) Simulation of daily variability of surface temperature and precipitation over Europe in the current and $2 \times \mathrm{CO}_{2}$ climates using the UKMO climate model. Q J R M eteorol Soc 121:1451-1476

Hansen J , Fung I, Lacis A, Rind D, Lebedeff S, Ruedy R, Russell G, Stone P (1988) Global climate changes as forecast by Goddard Institute for Space Studies three-dimensional model. J Geophys Res 93:9341-9364

Houghton J T, Meira Filho LG, Callander BA, Harris N, Kattenberg A, Maskell K (eds) (1996) Climate change 1995: the science of climate change. Cambridge University Press, Cambridge

Hughes PY, Mason EH, Karl TR, Brower WA (1992) United States Historical Climatology Network Daily Temperature and Precipitation Data. ORNL/CDIAC-50, NDP-042. Carbon Dioxide Information Analysis Center, Oak Ridge National Laboratory, Oak Ridge, TN

J ones PD (1994) Hemispheric surface air temperature variations: a reanalysis and an update to 1993. J Clim 7: 1794-1802

Joubert AM, Hewitson BC (1997) Simulating present and future climates of southern Africa using general circulation models. Prog Phys Geogr 21:51-78

Karl TR, Knight RW, Plummer N (1995) Trends in highfrequency climate variability in the twentieth century. Nature 377:217-220

Karl TR, Nicholls N, Gregory J (1997) The coming climate. Scient Am, May 79-83

Kerr RA (1997) Greenhouse forecasting still cloudy. Science 276:1040-1042

Knappenberger PC, Michaels PJ, Schwartzman PD (1996) Observed changes in the diurnal temperature and dewpoint cycles across the United States. Geophys Res Lett 23:2637-2640

Manley G (1974) Central England temperatures: monthly means 1659 to 1973. Q J R M eteorol Soc 100:389-405

Mearns LO, Katz RW, Schneider SH (1984) Extreme high temperature events: changes in their probabilities with changes in mean temperature. J Clim Appl Meteorol 23: 1601-1613

M earns LO, Schneider SH, Thompson SL, M cDaniel LR (1990) Analysis of climate variability in general circulation models: comparison with observation and changes in vari- 
ability in $2 \times \mathrm{CO}_{2}$ experiments. J Geophys Res 95: 20469-20490

Mitchell JFB, Johns TC (1997) On modification of global warming by sulfate aerosols. J Clim 10:245-266

Parker DE, J ones PD, Folland CK, Bevan A (1994) Interdecadal changes of surface temperature since the late nineteenth century. J Geophys Res 99:14373-14399

Parker DE, Legg TP, Folland CK (1992) A new daily central England temperature series, 1772-1991. Int J Climatol 12: 317-342

Editorial responsibility: Chris de Freitas,

Auckland, New Zealand
Razuvaev VN, Apasove EG, Martuganov RA (1993) Daily temperature and precipitation data for 223 USSR stations. ORN L/CDIAC-56, NDP-040. Carbon Dioxide Information Analysis Center, Oak Ridge National Laboratory, Oak Ridge, TN

Tarleton LF, Katz RW (1995) Statistical explanation for trends in extreme summer temperatures at Phoenix, Arizona. J $C \lim$ 8:1704-1708

Thompson DJ (1995) The seasons, global temperature and precession. Science 268:59-68

Submitted: J uly 15, 1997; Accepted: February 3, 1998

Proofs received from author(s): M arch 24, 1998 